\title{
Влияние модифицированной управляемой реперфузии на системный воспалительный ответ при острой ишемии конечности
}

\author{
О. А. Зарудный ${ }^{1}$ Ю. В. Иванова ${ }^{1}$, Б. В. Гилёв ${ }^{2}$ \\ ${ }^{1}$ Институт общей и неотложной хирургии имени В. Т. Зайцева НАМН Украины, г. Харьков, \\ ${ }^{2}$ Харьковский национальный университет имени В. Н. Каразина
}

\section{The impact of modified governed reperfusion on systemic inflammatory answer in an acute ischemia of the extremity}

\author{
O. A. Zarudny ${ }^{1}$, Yu. V. Ivanova ${ }^{1}$, B. V. Gilov ${ }^{2}$ \\ ${ }^{1}$ Zaytsev Institute of General and Urgent Surgery, Kharkov, \\ ${ }^{2}$ Karazin Kharkov National University
}

\begin{abstract}
Реферат
Цель. Изучить возможность уменышения неблагоприятных эффектов реперфузии на отдаленные органы и системы при острой ишемии конечности.

Материалы и методы. В исследование, проведенное в Институте общей и неотложной хирургии имени В. Т. Зайцева, включены 37 пациентов, оперированных в период с 2016 по 2019 г. по поводу тяжелой острой ишемии вследствие острой проксимальной окклюзии артерий нижней конечности. В 1 -й группе (сравнительной) 23 пациентам проводили стандартное лечение. У 14 пациентов 2-й группы (основной) во время восстановления кровотока применяли предложенную методику модифицированной управляемой реперфузии в комбинации с малопоточным гемодиализом в первые 12 ч реперфузионного периода. Изучали динамику концентрации интерлейкинов (IL-1 $\beta$, IL-6, IL-8, IL-10) и фактора некроза опухоли альфа (TNF- $\alpha$ ) в течение 48 ч после операции в периферической венозной крови. Также в раннем послеоперационном периоде оценивали уровни миоглобина, общей креатинфосфокиназы, креатинина и калия. Результаты. В раннем реперфузионном периоде наблюдали повышение концентрации провоспалительных цитокинов в сыворотке крови, особенно IL-6 и IL-8. Применение предложенного метода управляемой реперфузии позволило в течение первых 2 сут снизить концентрацию IL-6 на 51 - 67\%, а концентрацию IL-8 - на треть. Также при применении предложенной методики существенно снижались как пиковые, так и средние показатели уровней миоглобина и общей креатинфосфокиназы в сыворотке периферической крови. Клинически отмечено уменьшение тяжести почечной дисфункции и количества неблагоприятных сердечно-легочных событий.

Выводы. Применение разработанного метода управляемой реперфузии приводит к уменьшению воспалительного ответа и системного влияния продуктов ишемического метаболизма и рабдомиолиза в раннем послеоперационном периоде у пациентов с тяжелой ишемией нижних конечностей.

Ключевые слова: реперфузионное повреждение; острая ишемия; контролируемая реперфузия; интерлейкины.

Abstract

Objective. To study up a possibility of reduction of unfavorable effects of reperfusion on distant organs and systems in an acute ischemia of the extremity.

Materials and methods. In the investigation, conducted in the Zaytsev Institute of General and Urgent Surgery 37 patients were included, operated in 2016 - 2019 yrs for severe acute ischemia due to an acute proximal occlusion of the lower extremity artery. In the Group I (comparative) 23 patients the standard treatment was conducted. In 14 patients of the Group II (the main) during the blood flow restoration, the proposed procedure of modified governed reperfusion in combination with a lowflow hemodialysis was applied in the first $12 \mathrm{~h}$ of reperfusion period. Dynamics of concentration of interleukins (IL-1 $\beta$, IL-6, IL-8, IL-10) and the tumor necrosis factor alpha (TNF- $\alpha$ ) during $48 \mathrm{~h}$ after the operation in peripheral venous blood was registered. As well in early postoperative period the levels of myoglobin, general creatinphosphokinase, creatinine and potassium were estimated as well.

Results. Raising of concentration of anti-inflammatory cytokines in the blood serum, peculiarly of IL-6 and IL-8, was registered. Application of the method proposed for the governed reperfusion have permitted during first two days to lower concentration of IL -6 by $51-67 \%$, and concentration of IL- 8 - by the third part. While application of the method proposed the essential lowering of maximal and the average indices of levels of myoglobin and general creatinphosphokinase in the peripheral blood serum was noted as well. Reduction of the renal dysfunction severity and quantity of unfavorable cardio-pulmonary events was noted clinically.

Conclusion. Application of the elaborated method of the governed reperfusion leads to reduction of inflammatory answer and systemic impact of products of ischemic metabolism and rhabdomyolysis in early postoperative period in patients, suffering severe ischemia of lower extremities.

Key words: reperfusional damage; acute ischemia; controlled reperfusion; interleukins.
\end{abstract}


Острая ишемия нижних конечностей характеризуется высокой заболеваемостью и смертностью, несмотря на совершенствование хирургических методов и оптимизацию протоколов лечения таких больных [1]. Заболеваемость и смертность в раннем послеоперационном периоде во многом связаны с метаболическими нарушениями во время реперфузии после хирургической реваскуляризации. Экспериментальные и клинические данные свидетельствуют о том, что системные эффекты реперфузии имеют метаболические, воспалительные и тромботические компоненты, которые первоначально инициируются локально в ишемизированной конечности и соответственно требуют многокомпонентного корригирующего воздействия $[2,3]$.

Поэтому предложенная нами экстракорпоральная схема для реперфузионной терапии включает в себя контур артериальной перфузии и венозный дренаж оттекающей из конечности венозной крови через контур для продленного гемодиализа. Также мы предлагаем продолжать малопоточный гемодиализ, используя центральные или периферические венозные катетеры в раннем послеоперационном периоде.

Цель исследования: изучить возможность предложенного подхода уменьшить неблагоприятные эффекты реперфузии на отдаленные органы и системы у больных с тяжелой острой ишемией нижних конечностей.

\section{Материалы и методы исследования}

Нами проведено проспективное исследование у 37 пациентов, которые находились на лечении в отделении острых заболеваний сосудов Института общей и неотложной хирургии имени В. Т. Зайцева с 2016 по 2019 г. по поводу острого тромбоза или эмболии подвздошных или бедренных артерий нижних конечностей со IIB степенью острой ишемии по Резерфорду. В исследование включали пациентов, которым в ургентном порядке была выполнена хирургически успешная тромбэктомия, соответствующих критериям исследования и подписавших форму информированного согласия, без перемежающей хромоты в анамнезе, с длительностью ишемии более 6, но не более 12 ч. Критерием успешности реваскуляризации было восстановление магистрального артериального кровотока по поверхностной бедренной и/или глубо- кой бедренной артериям. Пациенты были разделены на две группы по мере поступления и технической возможности выполнить описанную ниже экстракорпоральную процедуру (табл. 1). В 1-й группе было 23 (62,2\%) пациента: мужчин - 10 (43,5\%), женщин - 13 (56,5\%). Средний возраст пациентов составил 72,3 года, длительность ишемии $(\overline{\mathrm{x}} \pm \sigma)-(7,2 \pm 0,6)$ ч, уровень креатинина при поступлении $(\overline{\mathrm{x}} \pm \sigma)-(104 \pm 18)$ мкмоль/л. Во 2-й группе было 14 (37,8\%) пациентов: мужчин - 7 (50\%), женщин - 7 (50\%). Средний возраст пациентов составил 69,8 года, длительность ишемии $(\overline{\mathrm{x}} \pm \sigma)-(7,5 \pm 0,7)$ ч, уровень креатинина при поступлении $(\overline{\mathrm{x}} \pm \sigma)-(112 \pm 22)$ мкмоль/л. Все пациенты были оперированы под спинальной анестезией. Длительность пережатия артерий в 1-й группе составила $(26 \pm 9)$ мин, во 2-й - (78 \pm 14$)$ мин.

Пациентам 1-й группы выполнили открытую тромбэктомию из бедренных и/или подвздошных артерий с закрытием артериотомной раны поперечным швом или с пластикой аутовенозной заплатой. В послеоперационном периоде больным проводили общепринятое лечение с ранней стимуляцией диуреза петлевыми диуретиками, внутривенной инфузией маннита, натрия гидрокарбоната, стандартной инфузионной и антикоагулянтной терапией.

Всем больным 2-й группы была выполнена открытая тромбэктомия с пластикой артериотомной раны аутовенозной заплатой. Проекционным доступом выделяли общую бедренную артерию и ее бифуркацию, дополнительно - сегмент общей бедренной вены до 4 - 5 см длиной (рис. 1), на проксимальном и дистальном участках которого накладывали кисетные швы для канюляции бедренной вены. Между кисетными швами на бедренной вене непосредственно перед началом реперфузии накладывали сосудистый зажим, забирая оттекающую от ишемизированной конечности кровь и реперфузат в аппарат для CRRT. На этапе пережатия артерий начинали системную гепаринизацию внутривенным болюсным введением гепарина в дозе 80 ЕД/кг массы тела (с учетом «остаточного» гепарина после подготовки экстракорпоральных контуров его общая доза достигала 100 - 130 ЕД/кг). После выполнения тромбэктомии из артерий дистальнее места артериотомии (или ревизии катетером Фогарти) выполняли канюляцию общей бедренной вены двумя ка-

\begin{tabular}{|c|c|c|c|c|}
\hline \multirow{3}{*}{ Параметры } & \multicolumn{4}{|c|}{ Группа больных } \\
\hline & \multicolumn{2}{|c|}{ 1-я } & \multicolumn{2}{|c|}{ 2-я } \\
\hline & абс. & $\%$ & абс. & $\%$ \\
\hline \multicolumn{5}{|l|}{ Сопутствующие заболевания } \\
\hline гипертоническая болезнь & 21 & 91,3 & 14 & 100 \\
\hline сахарный диабет & 8 & 34,8 & 4 & 28,6 \\
\hline инфаркт миокарда в анамнезе & 12 & 52,2 & 6 & 42,9 \\
\hline мерцательная аритмия & 20 & 87,0 & 13 & 92,9 \\
\hline \multicolumn{5}{|c|}{ Проксимальный уровень острой окклюзии } \\
\hline подвздошная артерия & 9 & 39,1 & 6 & 42,9 \\
\hline общая бедренная артерия & 14 & 60,9 & 8 & 57,1 \\
\hline
\end{tabular}




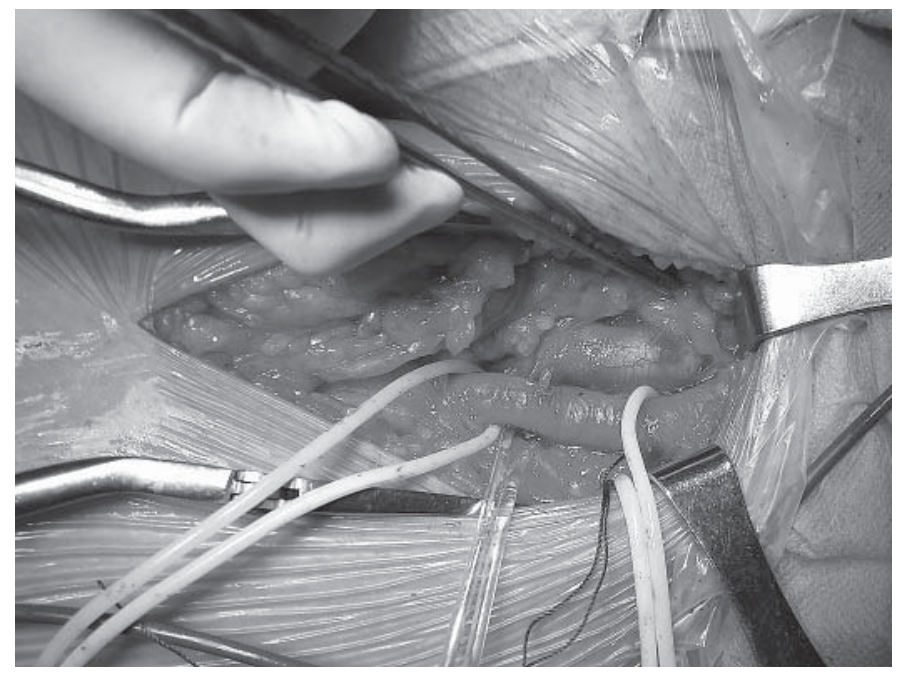

Puc. 1.

Доступ кобщей бедренной артерии (взята на держалки) с выделением сегмента общей бедренной вены.

нюлями Medtronic DLP 67316 (16 Fr), кисетные швы подтягивали турникетами (рuс. 2), общую бедренную вену пережимали между канюлями и начинали выполнять циркуляцию в режиме непрерывного малопоточного веновенозного хай-флакс гемодиализа (CVVHFD) на аппаpaтe Diapact CRRT (B. Braun) с низкой скоростью потока крови и скоростью ультрафильтрации около 20\% от скорости потока крови. После этого через артериотомную рану в просвет общей бедренной артерии устанавливали одну канюлю в дистальном направлении (канюля для ретроградной кардиоплегии с раздувающейся манжеткой Medtronic GUNDRY 15 Fr 94115T) или через артериотомную рану общей бедренной артерии раздельно канюлировали поверхностную и глубокую бедренные артерии (канюли для ретроградной кардиоплегии Medtronic DLP 6-10 Fr (puc. 3).

Реперфузию конечности начинали сразу после выполнения тромбэктомии из дистальных сегментов бедренной и подколенной артерий. Для этого вначале перфузировали 500 мл кристаллоидного раствора, содержащего гепарин, маннит, натрия бикарбонат, глюкозу и димексид, со скоростью 200 - 300 мл/мин с давлением не выше 70 мм рт. ст. Одновременно с этим соответственно увеличивали скорость потока крови в контуре гемодиализа и устанавливали максимально возможную скорость ультрафильтрации. В начале гемодиализа дополнительно вводили клексан/фленокс 0,5 мг/кг в «артериальную» линию гемодиализного контура. Использовали диализаторы HI PS 18 (B. Braun), в качестве диализата применяли гемодиафильтрационный раствор на основе бикарбонатного буфера Duosol (B. Braun). Если уровень гематокрита в оттекающей из диализатора крови был ниже 27 - 28\%, возврат крови в общую бедренную вену прекращали и перенаправляли в накопительный мешок. После выполнения «проксимального» этапа тромбэктомии и получения антеградного магистрального кровотока через артериотомную рану проксимально в направлении под-

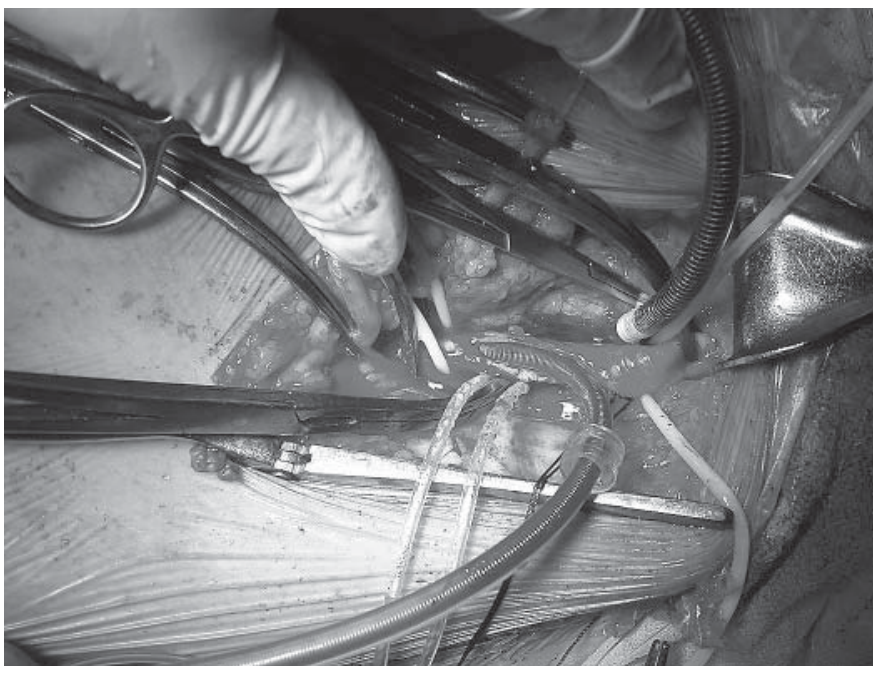

Puc. 2 .

Подключение экстракорпоральных контуров

для управляемой реперфузии (возврат венозной крови осуществляется через центральный венозный катетер).

вздошных артерий вводили канюлю для ретроградной кардиоплегии Medtronic DLP 8 - 10 Fr для забора артериальной крови. После введения инициальной дозы реперфузата (500 мл) начинали перфузию 1000 мл реперфузата с on-line примешиванием артериальной крови в соотношении 5:1 (в состав «основного» раствора для ре-

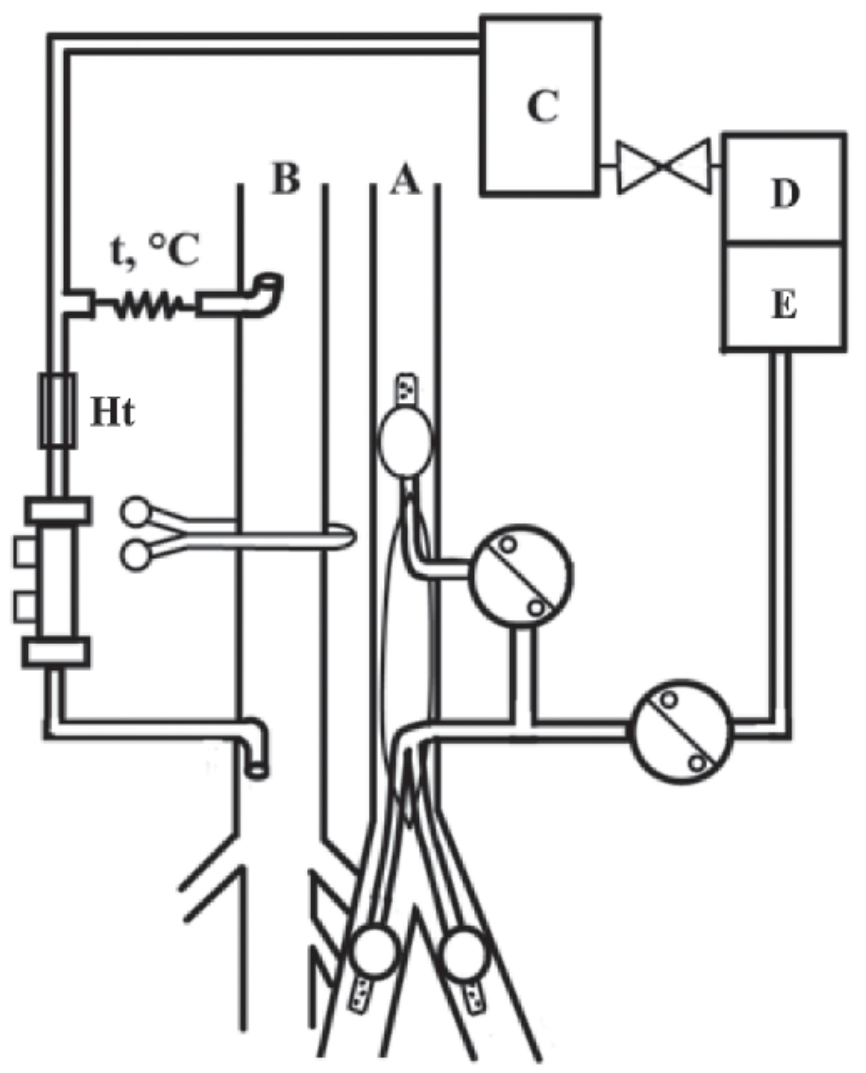

Puc.3.

Схема контролируемой реперфузии нижней конечности: $A$ - бедренная артерия, $B$ - бедренная вена, С - накопительный мешок, D и Е мешки с кристаллоидным реперфузатом, Ht - гематокритный датчик. 
перфузии дополнительно вводили 63 мл антикоагулянта ЦФДА-1). Все растворы, которые подавались для реперфузии, были комнатной температуры $\left(20-25^{\circ} \mathrm{C}\right)$. После прокачки указанных растворов продолжали перфузию из накопительного мешка, сохраняя соотношение примешивания артериальной крови. Таким образом, реперфузат некоторое время циркулировал через накопительный мешок для вытеснения избыточного количества жидкости. Когда гематокрит достигал уровня 0,38 - 0,4, оттекающую от диализатора кровь перенаправляли в общую бедренную вену (системное венозное русло), предварительно согрев в теплообменнике диализного контура до $37,5-38{ }^{\circ} \mathrm{C}$. Процедуру продолжали до опустошения накопительного мешка, после чего удаляли артериальные канюли и закрывали артериотомную рану, восстанавливали кровоток. Гемодиафильтрация со снятым с общей бедренной вены сосудистым зажимом продолжалась до окончания этапа гемостаза. После этого линии для CVVHFD с бедренных вен переключали на доступы к периферическим/центральным венам и продолжали CVVHFD в течение 12 ч после начала реперфузии. С третьего часа гемодиализа начинали инфузию гепарина в экстракорпоральный контур под контролем АСТ (целевое значение 160 - 200 с). С учетом режима антикоагуляции при использовании описанной экстракорпоральной технологии фасциотомию на голени выполняли до интраоперационного введения гепарина и этапа тромбэктомии.

У пациентов обеих групп определяли уровни калия и креатинина в плазме крови, взятой из периферической вены, до операции, через 12 и 24 ч после восстановления кровотока. Уровень калия в сыворотке крови определялся ионометрически с применением ионоселективных электродов. Также до операции, через 6 (во 2-й группе во время CVVHFD) и 24 ч после восстановления кровотока определяли уровни миоглобина и общей креатинфосфокиназы (КФК) в плазме крови. Уровень общей КФК определяли кинетическим методом.

Концентрацию интерлейкинов (IL-1 $\beta$, IL-6, IL-8, IL10) и фактора некроза опухоли альфа (TNF- $\alpha)$ оценивали в периферической венозной крови до операции, а так- же через 3, 6, 12, 24 и 48 ч после восстановления кровотока. Уровни миоглобина, TNF- $\alpha$, IL-1 $\beta$, IL-6, IL-8, IL-10 определяли иммуноферментным методом на анализатоpe STAT FAX 3200 (США) наборами реагентов для иммуноферментного определения концентраций указанных веществ в сыворотке крови компании «ВЕКТОР-БЕСТ» (Россия). По заявлению производителя минимальная обнаруживаемая концентрация для TNF- $\alpha-1$ пг/мл, IL-1 $\beta$ - 1 пг/мл, IL-6 - 0,5 пг/мл, IL-8 - 2 пг/мл, IL-10 - 1 пг/ мл, диапазон измеряемых концентраций - 0-250 пг/мл, 0-250 пг/мл, 0-300 пг/мл, 0-250 пг/мл, 0-500 пг/мл соответственно. Коэффициент вариации результатов определения содержания указанных показателей не более 8\%.

Накопление, систематизацию исходной информации и визуализацию полученных результатов осуществляли в электронных таблицах Microsoft Office Excel 2007. Статистический анализ проводили с использованием программы IBM SPSS Statistics v.23 (США).

При сравнении средних величин количественных данных рассчитывали двухвыборочный t-критерий Стьюдента, который оценивали путем сравнения с критическими значениями. Различия показателей считали статистически значимыми, если уровень значимости р был меныше 0,05.

\section{Результаты}

В раннем реперфузионном периоде у пациентов обеих групп выявлено повышение концентрации исследуемых цитокинов (табл. 2). Динамика концентрации IL-6 у пациентов 1-й группы характеризовалась стремительным повышением в течение первых 10 - 12 ч с достижением пиковых значений - $(77,6 \pm 19,7)$ пг/мл и достаточно быстрым понижением в последующие 36 ч наблюдения. К концу 2-х суток концентрация IL-6 уже составляла приблизительно половину от пиковых значений. У пациентов 2-й группы концентрация IL-6 в течение всего периода наблюдения была значительно меньшей и к 6-ти часам практически достигала максимальных значений. В последующие 12 и 24 ч концентрация IL-6 существенно не изменялась, а через 48 ч демонстрировала значительное снижение.

\begin{tabular}{|c|c|c|c|c|c|c|c|}
\hline \multirow{2}{*}{ Цитокины } & \multirow{2}{*}{$\begin{array}{l}\text { Группа } \\
\text { больных }\end{array}$} & \multirow{2}{*}{ До операции } & \multicolumn{5}{|c|}{ Длительность реперфузии, ч } \\
\hline & & & 3 & 6 & 12 & 24 & 48 \\
\hline \multirow[t]{2}{*}{ IL-1 $\beta$} & $1-9$ & $6,6 \pm 0,9$ & $7,8 \pm 1,1^{*}$ & $8,5 \pm 1,2 *$ & $8,3 \pm 1,0 *$ & $9,1 \pm 1,6^{*}$ & $8,7 \pm 1,8^{*}$ \\
\hline & 2-я & $6,2 \pm 1,1$ & $6,9 \pm 0,8$ & $6,1 \pm 0,7$ & $5,5 \pm 0,6$ & $6,3 \pm 0,9$ & $6,4 \pm 0,8$ \\
\hline \multirow[t]{2}{*}{ IL-6 } & 1-я & $8,2 \pm 1,9 *$ & $12,9 \pm 2,6 *$ & $55,3 \pm 14,3^{*}$ & $77,6 \pm 19,7^{*}$ & $64,9 \pm 16,5^{*}$ & $43,7 \pm 11,1^{*}$ \\
\hline & 2-я & $9,8 \pm 2,1$ & $8,3 \pm 1,6$ & $27 \pm 6,2$ & $25,3 \pm 7,1$ & $30,6 \pm 7,8$ & $17 \pm 3,2$ \\
\hline \multirow[t]{2}{*}{ II-8 } & 1-я & $13,2 \pm 1,7$ & $13,7 \pm 1,9 *$ & $18,3 \pm 2,8^{*}$ & $23,3 \pm 3,1^{*}$ & $28,6 \pm 3,4^{*}$ & $30,4 \pm 3,8^{*}$ \\
\hline & 2-я & $14,1 \pm 2,0$ & $11,2 \pm 1,6$ & $14,1 \pm 1,5$ & $15,8 \pm 1,9$ & $16,2 \pm 1,9$ & $19,8 \pm 2,6$ \\
\hline \multirow[t]{2}{*}{ IL-10 } & 1-я & $2,3 \pm 0,5$ & $2,5 \pm 0,5$ & $2,9 \pm 0,7$ & $7,4 \pm 2,2$ & $13,6 \pm 4,7$ & $24,2 \pm 9,2$ \\
\hline & 2-я & $2,1 \pm 0,3$ & $2,4 \pm 0,6$ & $2,6 \pm 0,8$ & $6,2 \pm 1,6$ & $14,5 \pm 2,9$ & $29,4 \pm 6,4$ \\
\hline \multirow[t]{2}{*}{ TNF- $\alpha$} & 1-я & $15,7 \pm 2,0$ & $19,2 \pm 2,8$ & $24,3 \pm 7,5^{*}$ & $25,4 \pm 8,0 *$ & $24,8 \pm 8,4^{*}$ & $25,1 \pm 7,7^{*}$ \\
\hline & $2-9$ & $16,3 \pm 2,2$ & $17,6 \pm 1,9$ & $18,9 \pm 2,0$ & $16,3 \pm 2,5$ & $18,1 \pm 3,1$ & $17,4 \pm 2,7$ \\
\hline
\end{tabular}




\begin{tabular}{|c|c|c|c|c|}
\hline \multirow{2}{*}{ Показатель } & \multirow{2}{*}{ Группа больных } & \multirow{2}{*}{ До операции } & \multicolumn{2}{|c|}{ После операции } \\
\hline & & & через 64 & через 24 ч \\
\hline \multirow{2}{*}{ Миоглобин, пг/мл } & 1-я & $276 \pm 102$ & $1788 \pm 584 *$ & $761 \pm 292^{*}$ \\
\hline & 2-я & $291 \pm 94$ & $568 \pm 168$ & $346 \pm 96$ \\
\hline \multirow{2}{*}{ КФК, Ед/л } & 1-я & $1364 \pm 402$ & $5802 \pm 1950 *$ & $8462 \pm 2926 *$ \\
\hline & $2-9$ & $1198 \pm 378$ & $3980 \pm 1268$ & $5026 \pm 1540$ \\
\hline
\end{tabular}

Динамика концентрации IL-8 у пациентов обеих групп характеризовалась неуклонным повышением значений в течение всего периода наблюдения, при этом с увеличением длительности реперфузии различие концентраций IL-8 становилось значительнее.

Концентрации IL-10 и TNF- $\alpha$ у пациентов 2-й группы в первые 2 сут реперфузии несущественно отличались от исходных, в то время как у пациентов 1-й группы они были повышены. Уменышение концентрации IL-10 и TNF- $\alpha$ через 12 ч реперфузии, вероятно, было связано с фильтрацией/адсорбцией на мембране гемодиализной колонки и не наблюдалось после прекращения экстракорпоральной процедуры.

Мы не обнаружили значимых различий в величинах и динамике показателей IL-10 у пациентов обеих групп. Общей тенденцией было повышение концентрации IL10 через 24 ч реперфузии с дальнейшим выраженным приростом в течение 2 послеоперационных суток. Тем не менее к концу 2-х послеоперационных суток соотношение противовоспалительных цитокинов к провоспалительным у пациентов 2-й группы оказалось более благоприятным.

Концентрация миоглобина в сыворотке крови через 6 ч после операции была наибольшей (табл. 3). Выявлена существенно меньшая концентрация миоглобина у пациентов 2-й группы в течение 1 -х суток после восстановления кровотока, чем у пациентов $1-$ й группы. Уровень общей КФК в первые 24 ч после операции у больных 2-й группы также был ниже, чем у больных 1-й группы, хотя не столь значительно, как концентрации миоглобина.

Уровень калия в сыворотке крови через 12 ч после операции у пациентов $1-$ й группы составил $(4,5 \pm 0,5)$ ммоль/л, у пациентов 2-й группы - $(3,9 \pm 0,3)$ ммоль/л, через 24 ч - $(4,9 \pm 0,6)$ и $(4,4 \pm 0,7)$ ммоль/л соответственно. Уровень креатинина через 12 и 24 ч после операции

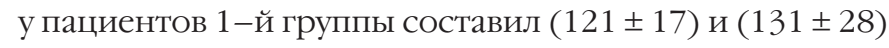
мкмоль/л соответственно, у пациентов 2-й группы - (92 $\pm 12)$ и $(108 \pm 22)$ мкмоль/л соответственно.

Во время нахождения на лечении в стационаре признаки той или иной степени почечной дисфункции были выявлены у 78,3\% пациентов 1-й группы и у 71,4\% пациентов 2-й группы. Признаки легкой почечной дисфункции (І стадия острого повреждения почек по классификации AKIN) наблюдали у 11 (47,8\%) пациентов 1-й группы, значительные проявления почечной недостаточности у 5 (21,7\%), интермиттирующие процедуры гемодиализа понадобились 2 (8,7\%) пациентам. Легкую почечную дис- функцию отметили у 8 (57,1\%) пациентов 2-й группы, клинические проявления почечной недостаточности - у 2 (14,3\%). Пациентам 2-й группы дополнительная заместительная почечная терапия не понадобилась.

Из-за неблагоприятных сердечно-легочных событий, которые развились в раннем послеоперационном периоде, 6 (26,1\%) пациентов 1-й группы и 2 (14,3\%) пациента 2 -й группы находились в палате интенсивной терапии более 1 сут после операции.

Количество ампутаций в 1-й и 2-й группе было сопоставимым - у $3(13,0 \%)$ и 2 (14,3\%) больных соответственно.

Летальность в обеих группах также достоверно не отличалась. В 1-й группе умерли 2 (8,7\%) пациента, во 2-й группе - 1 (7,1\%). В 1-й группе у 1 больного причиной смерти был инфаркт миокарда, у 1 - полиорганная недостаточность. Во 2-й группе причиной смерти пациента был ишемический инсульт.

\section{Обсуждение}

Концепцию «контролируемой реперфузии» впервые разработали F. Beyersdorf и соавторы в 1989 г. [4]. Теоретической основой контролируемой реперфузии стали экспериментальные исследования на животных и клинические сообщения, которые демонстрировали, что ограничение первоначального давления и скорости реперфузии, а также модификация состава перфузата могут предотвратить некротические процессы в мышечной ткани ишемизированной конечности, уменышить летальность и частоту ампутации [5]. Эффект посткондиционирования в уменьшении ишемически-реперфузионного повреждения выявлен и экспериментально доказан для большинства тканей и органов человека и животных, в том числе для скелетной мышечной ткани [6].

Несмотря на обнадеживающие начальные результаты применения управляемой реперфузии у человека, рандомизированное многоцентровое исследование CRAIL для простой схемы реперфузии не показало преимуществ в сохранении конечности и снижении летальности $[7,8]$.

Успех экспериментальных работ и разочарование, вызванное CRAIL, имеют несколько причин. Во-первых, абсолютная ишемия при пережатии сосудистой ножки тканевого лоскута или перевязке артерии конечности экспериментального животного кардинально отличается от, как правило, неполной ишемии реального пациента с различными вариантами коллатерального кровотока. Во-вторых, рутинное применение данной техноло- 
гии, вероятно, не оправдано и избыточно. Также играли роль многочисленные нарушения протокола и несоответствие рапортируемых данных предваряющим клиническим исследованиям.

Принятие решения о нежизнеспособности конечности и ампутации оперирующим хирургом имеет качественный характер, тогда как различные схемы контролируемой реперфузии, в том числе и предложенная нами, предполагают количественное уменьшение локальных и системных ишемически-реперфузионных повреждений. В то же время при устранении эмбола из артерии рециркуляция в ишемизированных тканях носит мозаичный характер, и этот процесс может происходить в течение 1 3 сут. Большой относительный объем мышечной ткани нижней конечности непосредственно угрожает жизни пациента даже при частичном рабдомиолизе.

Избыточная продукция цитокинов и других провоспалительных медиаторов в постишемическом периоде может привести к синдрому системного воспалительного ответа (SIRS) с поражением «отдаленных» органов, в первую очередь легких и сердца. Особый интерес представляют TNF- $\alpha$ и IL-1 $\beta$, которые считаются основными медиаторы SIRS, а также IL-6.

Предложенная методика продемонстрировала способность к снижению уровней основных провоспалительных цитокинов в системном кровотоке в раннем послеоперационном периоде, особенно IL-6 и IL-8, которые в значительной степени продуцируются непосредственно в тканях ишемизированной конечности. Также показательно снижение концентрации миоглобина в течение 1 -х суток послеоперационного периода. С учетом того, что хай-флакс мембрана диализатора имеет низкий клиренс для большинства цитокинов и миоглобина, полученные данные также могут свидетельствовать об уменьшении степени локального реперфузионного повреждения и рабдомиолиза в ишемизированной конечности при применении предложенной методики.

С учетом изложенного представляется наиболее перспективным применение предложенной экстракорпоральной схемы для реперфузионной терапии при тромбозе аорты с блокированием коллатералей и развитием острой ишемии нижних конечностей, у пациентов с двусторонней эмболией подвздошно-бедренного сегмента, в группе пациентов высокого риска с проксимальной острой окклюзией со IIB степенью ишемии давностью более 6 ч $[9,10]$.

Трудно определить жизнеспособность тканей на основании клинического обследования в условиях тяжелой острой ишемии, когда у хирурга остается очень мало времени для дополнительных методов исследования. В этой ситуации, если хирург склонен отдать предпочтение реваскуляризации для попытки спасти ишемическую конечность, предложенная методика может позволить уменьшить риски со стороны жизненно важных органов, в том числе до выполнения отсроченной ампутации.

\section{Выводы}

Применение предложенной методики реперфузии в сочетании с непрерывным вено-венозным малопоточным хай-флакс гемодиализом позволяет уменьшить выраженность воспалительного ответа и системное влияние продуктов ишемического метаболизма и рабдомиолиза в раннем послеоперационном периоде у пациентов с тяжелой ишемией нижних конечностей.

\section{Подтверждение}

Финансирование. Личные средства.

Информация о вкладе каждого участника. Зарудный О. А. - концепция исследования, написание текста; Иванова Ю. В. - дизайн исследования, анализ полученных данных; Гилёв Б. В. - набор и обработка материалов клинического исследования.

Конфликт интересов. Авторы статьи, представленной к публикации, декларируют отсутствие конфликта интересов.

Согласие на публикацию. Все авторы дали согласие на публикацию этой рукописи.

\section{References}

1. Biancari F. Meta-analysis of the prevalence, incidence and natural history of critical limb ischemia. J Cardiovasc Surg (Torino) 2013;54(6):6639. PMID: 24126504.

2. Kutepov DE, Zhigalova MS, Pasechnik IN. Patogenez sindroma ishemiireperfuzii [Pathogenesis of ischemia-reperfusion syndrome]. Kazanskij med. zh. 2018;99 (4):640-44. doi: 10.17816/KMJ2018-640. [In Russian].

3. Genyk SM, Symchych AV. Reperfusion syndrome after revascularization of lower extremity ischemia. Serce i sudyny. 2016;3:104-8. [In Ukrainian].

4. Beyersdorf F, Matheis G, Kruger S, Hanselmann A, Freisleben HG, Zimmer $\mathrm{G}$, et al. Avoiding reperfusion injury after limb revascularization: experimental observations and recommendations for clinical application. J Vasc Surg 1989;9(6):757-66. PMID: 2657120.

5. Dick F, Li J, Giraud MN, Kalka C, Schmidli J, Tevaearai H. Basic control of reperfusion effectively protects against reperfusion injury in a realistic rodent model of acute limb ischemia. Circulation. 2008;118(19):1920 8. doi: 10.1161/CIRCULATIONAHA.108.787754.

6. Baines C.P. How and when do myocytes die during ischemia and reperfusion: the late phase. J Cardiovasc Pharmacol Ther. 2011;16 (3-4):239 43. doi: $10.1177 / 1074248411407769$.

7. Walker PM, Romaschin AD, Davis S, Piovesan J. Lower limb ischemia: phase 1 results of salvage perfusion. J Surg Res. 1999;84(2):193-8. doi: 10.1006/jsre.1999.5641.

8. Heilmann C, Schmoor C, Siepe M, Schlensak C, Hoh A, Fraedrich G et al. Controlled reperfusion versus conventional treatment of the acutely ischemic limb: results of a randomized, open-label, multicenter trial. Circ Cardiovasc Interv. 2013;6(4):417-27. doi: 10.1161/CIRCINTERVENTIONS.112.000371.

9. Mutirangura P, Chinsakchai K, Wongwanit C, Ratanaratb R, Ruangsetakit C. Successful revascularization with intraoperative venous drainage of ischemic limbs through hemodialysis in severe acute saddle aortic embolism. Eur J Vasc Endovasc Surg. 2010;39(1):123. doi:10.1016/j.ejvs.2009.09.017

10. Schmidt CA, Rancic Z, Lachat ML, Mayer DO, Veith FJ, Wilhelm MJ. Hypothermic, initially oxygen-free, controlled limb reperfusion for acute limb ischemia. Ann Vasc Surg. 2015;29(3):560-72. doi: 10.1016/j. avsg.2014.09.033

Надійшла 12.06.19 